\title{
ANALISIS KUALITAS PELAYANAN TERHADAP KEPUASAN MAHASISWA PADA FAKULTAS EKONOMI UNIVERSITAS NEGERI YOGYAKARTA
}

\author{
Abdullah Taman ${ }^{1}$ \\ Sukirno $^{2}$ \\ Annisa Ratna Sari ${ }^{3}$ \\ Ngadirin Setiawan ${ }^{4}$ \\ Adeng Pustikaningsih 5
}

\section{Fakultas Ekonomi Universitas Negeri Yogyakarta}

\begin{abstract}
ABSTRAK
Penelitian ini mengkaji kualitas layanan yang disediakan oleh FE UNY dan pengaruhnya terhadap tingkat kepuasan mahasiswa studi di FE UNY. Lebih spesifik lagi, penelitian ini bertujuan untuk mengetahui pengaruh keandalan, ketulusan, jaminan, keberwujudan dan ketanggapan terhadap kepuasan mahasiswa.

Penelitian ini termasuk penelitian kausal-komparatif, yaitu penelitian untuk menguji variabel satu mempengaruhi varaibel lain. Pengumpulan data dilakukan dengan kuesioner yang dibagikan kepada para mahasiswa FE UNY dari semua program studi, baik S1 maupun D3, mahasiswa yang berkuliah di Kampus UNY Karangmalang, maupun di UNY Wates, dengan menggunakan metode proportional random sampling. Teknik analisis data dengan menggunakan regresi berganda, dengan melihat uji-t dan uji-F.

Hasil penelitian ini menyimpulkan bahwa terdapat pengaruh positif dan signifikan Keandalan terhadap Kepuasan mahasiswa; terdapat pengaruh positif dan signifikan Ketulusan terdahap Kepuasan mahasiswa;t idak terdapat pengaruh Jaminan terhadap Kepuasan mahasiswa; terdapat pengaruh positif dan signifikan Keberwujudan terhadap Kepuasan mahasiswa; terdapat pengaruh positif dan signifikan Ketanggapan terhadap Kepuasan mahasiswa. Secara simultan kelima variabel berpengaruh positif dan signifikan terhadap Kepuasan mahasiswa, dengan koefisien determinasi (R2) sebesar 0,814. Artinya, kelima variabel independen mempengaruhi variabel Kepuasan mahasiswa sebesar 81,4\%, sedangkan selebihnya $(18,6 \%)$ dipengaruhi oleh variabel lain yang tidak diteliti dalam penelitian ini.
\end{abstract}

Kata Kunci: kualitas pelayanan, kepuasan mahasiswa

\section{A. PENDAHULUAN}

\section{Latar Belakang Masalah}

Tidak jauh berbeda dari pelayanan publik oleh aparatur pemerintah di lembaba lain, Fakultas Ekonomi (FE) sebagai fakultas terbaru di Universitas Negeri Yogyakarta (UNY) masih banyak dijumpai kelemahan. Hal ini ditandai dengan masih adanya berbagai keluhan mahasiswa yang disampaikan baik melalui media verbal

\footnotetext{
${ }^{1}$ Staf Pengajar Jurusan P. Akuntansi Fakultas Ekonomi Universitas Negeri Yogyakarta

2 Staf Pengajar Jurusan P. Akuntansi Fakultas Ekonomi Universitas Negeri Yogyakarta

${ }^{3}$ Staf Pengajar Jurusan P. Akuntansi Fakultas Ekonomi Universitas Negeri Yogyakarta

${ }^{4}$ Staf Pengajar Jurusan P. Akuntansi Fakultas Ekonomi Universitas Negeri Yogyakarta

${ }^{5}$ Staf Pengajar Jurusan P. Akuntansi Fakultas Ekonomi Universitas Negeri Yogyakarta
} 
(demonstrasi, usulan dalam rapat) maupun nonverbal (tulisan pada majalah, banner), sehingga dapat menimbulkan citra yang kurang baik terhadap eksistensi FE.Mengingat fungsi utama fakultas adalah melayani kegiatan akademin dan nonakademik mahasiswa maka FE UNY perlu terus berupaya meningkatkan kualitas pelayanannya.

Penjaminan mutu pendidikan di perguruan tinggi adalah proses penetapan dan pemenuhan standar mutu pengelolaan pendidikan tinggi secara konsisten dan berkelanjutan, sehingga stakeholders (mahasiswa, orang tua, dunia kerja, pemerintah, dosen, tenaga penunjang, serta pihak lain yang berkepentingan) memperoleh kepuasan sebagaimana dikemukakan oleh Ponpon (2003).

Tuntutan bagi perguruan tinggi untuk memiliki organisasi yang sehat adalah merupakan salah satu strategic point dalam HELTS, 2003 - 2010 di mana " $a$ continuous quality improvement should become its primary concern."Hanya organisasi/ satuan pendidikan yang sehatlah yang dapat memberikan pelayanan yang baik bagi terjadinya "a continuous quality improvement"

Hal tersebut tercantum dengan jelas didalam Renstra Kemendiknas 2010 - 2014 dengan visi adalah “Terselenggaranya Layanan Prima Pendidikan Nasional untuk Membentuk Insan Indonesia yang Cerdas Komprehensif", sedangkan misinya yang adalah:

1. Meningkatkan Ketersediaan Layanan Pendidikan

2. Memperluas Keterjangkauan Laya nan Pendidikan

3. Meningkatkan Kualitas/Mutu dan Relevansi Layanan Pendidikan

4. Mewujudkan Kesetaraan dalam Memperoleh Layanan Pendidikan

5. Menjamin Kepastian Memperoleh Layanan Pendidikan

6. Melayani Semua dengan Amanah.

Mencermati pesan yang tertuang di dalam kedua renstra pendidikan tersebut mendorong dibentuknya lembaga penjamin mutu di perguruan tinggi dan kemudian menjadi salah satu syarat utama untuk dapat berkompetisi dalam berbagai penelitian hibah bersaing atau untuk memperoleh fasilitas lainnya bagi perguruan tinggi. Upaya yang penerapannya dilakukan secara bertahap ini diharapkan dapat meningkatkan mutu pendidikan perguruan tinggi, seperti dituangkan didalam PP 19 Tahun 2005 tentang SNP dalam pasal 91- tentang Penjaminan Mutu menyatakan bahwa:Setiap satuan pendidikan pada jalur formal dan nonformal wajib melakukan penjaminan mutu pendidikan. Penjaminan mutu 


\section{JURNAL NOMINAL / VOLUME II NOMOR I / TAHUN 2013}

pendidikan sebagaimana diimaksud pada ayat 1) bertujuan untuk memenuhi atau melampaui Standar Nasional Pendidikan.Penjaminan mutu pendidikan sebagaimana dimaksud pada ayat 1) dilakukan secara bertahap, sistematis, dara $n$ terencana dalam suatu program penjaminan mutu yang memiliki target dan kerangka waktu yang jelas.

Semakin meningkat kebutuhan masyarakat terhadap pendidikan formal, khususnya pendidikan tinggi, menjadikan perguruan tinggi sebagai sektor strategis yang diharapkan dapat menghasilkan sumber daya manusia yang bermutu.Keadaan persaingan yang cukup kompetitif antarperguruan tinggi menuntut lembaga pendidikan memperhatikan mutu pendidikan dan kelembagaan sehingga mampu serta unggul dalam persaingan tersebut (Srinadi dan Nilakusmawati, 2008). Perguruan Tinggi harus melakukan langkah antisipasi guna menghadapi persaingan yang semakin kompetitif serta bertanggung jawab untuk menggali dan meningkatkan segala aspek pelayanan yang dimiliki.

Penelitian mengenai berbagai permasalahan yang dihadapi perguruan tinggi dalam kaitannya dengan pengukuran mutu jasa, penilaian dengan pendekatan akreditasi serta penilaian yang sifatnya langsung seperti tingkat gagal studi (DO), masa studi dan lainnya dianggap tidak cukup sehingga diperlukan paradigma baru sebagai indikator pengukuran mutu (Sadat, 2002).Keberhasilan fakultas sebagai unit kerja dalam perguruan tinggi sangat ditentukan oleh mutu pelayanan yang diberikan.Pelayanan yang bermutu dapat diidentifikasi melalui kepuasan pelanggan, khususnya adalah mahasiswa (Srinadi dan Nilakusmawati, 2008).

Tjiptono (2000: 54) menyebutkan bahwa kualitas memiliki hubungan yang erat dengan kepuasan pelanggan.Kualitas memberikan suatu dorongan kepada pelanggan untuk menjalin ikatan hubungan yang kuat dengan perusahaan.Dalam jangka panjang, ikatan seperti ini memungkinkan perusahaan untuk memahami dengan seksama harapan pelanggan serta kebutuhan mereka.

FE UNY sebagai salah satu lembaga pendidikan tinggi negeri, harus menerapkan konsep mengutamakan kepuasan mahasiswa sebagai pelanggan dengan memberikan pelayanan terbaik. Beberapa bidang pelayanan yang harus dikembangkan secara berkelanjutan meliputi kurikulum program studi, proses pembelajaran, sumber daya manusia (dosen, pegawai, teknisi), mahasiswa, sarana dan prasarana, suasana akademik, penelitian serta publikasi, pelayanan masyarakat, sistem informasi, dan 
kerjasama dalam/luar negeri. Perhatian terhadap peningkatan kualitas sarana dan pelayanan dari waktu ke waktu menjadi semakin penting untuk kepuasan mahasiswa karena hal tersebut merupakan langkah awal keberhasilan perguruan tinggi di masa mendatang.

Mahasiswa FE UNY seringkali mengeluh tentang kualitas sarana dan pelayanan yang diberikan oleh fakultas.Mahasiswa merasakan bahwa pelayanan Fakultas Ekonomi jauh dari harapan mereka.Permasalahan dosen dalam ketepatan mengajar mahasiswanya, respon yang sangat lamban dari unsur-unsur fakultas menjadikan permasalahan mahasiswa menjadi lebih komplek, kelengkapan peralatan perkuliahan yang tidak begitu memadai, dan lain sebagainya.

Dengan demikian perguruan tinggi dapat meningkatkan kepuasan mahasiswa dengan cara meningkatkan kualitas sarana dan pelayanan yang sudah bagus serta memperbaiki yang masih lemah. Prioritas utama yang perlu diperhatikan kampus adalah kepuasan mahasiswa semaksimal mungkin.

\section{Rumusan Masalah}

Berdasarkan kepada kajian empiris dan teoritis pada bagian pendahuluan di atas, maka permasalahan penelitian ini adalah:

a. Bagaimana pengaruh keandalan terhadap kepuasan mahasiswa FE UNY?

b. Bagaimana pengaruh ketulusan terhadap kepuasan mahasiswa FE UNY?

c. Bagaimana pengaruh jaminan terhadap kepuasan mahasiswa FE UNY?

d. Bagaimana pengaruh keberwujudan terhadap kepuasan mahasiswa FE UNY?

e. Bagaimana pengaruh ketanggapan terhadap kepuasan mahasiswa FE UNY?

f. Bagaimana pengaruh keandalan, ketulusan, jaminan, keberwuju dan, ketanggapan terhadap kepuasan mahasiswa FE UNY?

\section{Kajian Teori}

\section{a. Dimensi Kualitas Pelayanan Perguruan Tinggi}

Dimensi kualitas pelayanan pada perguruan tinggi, Kotler \& Fox (1995: 414) mengemukakan bahwa terdapat enam dimensi utama dalam kualitas pelayanan pada perguruan tinggi, yaitu: quality of instruction, academic advising, library 
resources, extracurricular activity, opportunities to talk with faculty members, job placement services.

Lebih lanjut Kotler \& Fox memaparkan penjelasan keenam dimensi utama pelayanan pada Perguruan Tinggi tersebut sebagai berikut: 1) dimensi quality of instruction (kualitas pembelajaran) berkaitan dengan kemampuan dosen/instruktur dalam penguasaan materi, menyampaikan materi, keramahannya, objektivitas dalam memberikan nilai, dan sebagainya, 2) dimensi academic advising (bimbingan akademik) bertalian dengan dosen yang menjadi pembimbing akademik dalam hal kontinyuitas, kesabaran, ketelitian, dan ketersediaan waktu dalam memberikan bimbingan akademik, dan sebagainya, 3) dimensi library resources (sumber daya pendukung) meliputi ketersediaan laboratorium, perpustakaan, ruang kuliah, dan sebagainya, 4) dimensi extracurricular activity (aktivitas ekstra kurikuler) meliputi jumlah dan daya tarik berbagai aktivitas ekstra kurikuler, dukungan universitas terhadap kegiatan mahasiswa, dan sebagainya, 5) dimensi opportunities to talk with faculty members (aspek komunikasi dengan pimpinan/staf universitas) berkaitan dengan aspek kemudahan untuk menghubungi pimpinan/staf pada tingkat universitas, fakultas, jurusan atau program studi, 6) dimensi job placement services (aspek pelayanan administrasi) meliputi kemampuan dan kecepatan staf bagian administrasi pada tingkat universitas, fakultas, maupun jurusan atau program studi, dalam memberikan pelayanan.

\section{b. Kepuasan Mahasiswa}

Kepuasan Mahasiswa adalah suatu bentuk perasaan seseorang yang mendapatkan pengalaman kinerja (atau hasil) yang telah memenuhi harapannya, yang meliputi (Assauri, 2003): 1) Waktu yang digunakan untuk menunggu dilayani 2) Kecepatan dan ketepatan dalam pelayanan kepada mahasiswa 3) Ketepatan dalam melak-sanakan janji 4) Keramahan dan kesopanan pimpinan, dosen dan karyawan dalam bersikap dan berbicara 5) Pengetahuan dosen dan karyawan dalam pelayanan 6) Prosedur dalam pelayanan dan penyelesaian layanan 7) Kemudahan pimpinan, dosen dan karyawan dalam dihubungi 8) Tempat pelayanan nyaman, bersih bagi mahasiswa 9) Menciptakan kelancaran dalam pelayanan 10) Keramahan pelayanan berpengaruh terhadap kepuasan mahasiswa. 


\section{JURNAL NOMINAL / VOLUME II NOMOR I / TAHUN 2013}

\section{c. Keandalan}

Keandalan (reliability) adalah kemampuan Perguruan Tinggi untuk memberikan pelayanan yang sesuai dengan janji yang ditawarkan secara akurat, teliti, dan terpercaya, yang tercakup dalam item berikut: 1) Keakuratan Informasi pelayanan kegiatan belajar mengajar 2) Perlakuan terhadap mahasiswa tidak diskriminatif 3) Keakuratan dalam memberikan nilai hasil belajar 4) Proses dan Prosedur administrasi tidak rumit 5) Informasi yang dibutuhkan mahasiswa cepat diperoleh dan memuaskan (Assauri, 2003).

\section{d. Ketulusan}

Dalam bukunya, Assauri (2003) mendefiniskan ketulusan (empathy) sebagai cara-cara yang digunakan penyelenggaraan pelayanan untuk menunjukkan rasa peduli dan perhatian kepada pelanggannya tanpa pengaruh hubungan individual atau pribadi yang mencakup item 1) Sikap dan perilaku dosen dan karyawan baik 2) Tegur sapa dan tutur kata dosen dan karyawan dalam berkomunikasi 3) Kemudahan dosen dan karyawan dalam dihubungi 4) Etika lewat media komunikasi oleh dosen dan karyawan sudah baik 5) Dosen dan karyawan dalam memenuhi pelayanan yang mendesak baik.

\section{e. Jaminan}

Jaminan (assurance) adalah pengetahuan dan keahlian dosen dan karyawan serta kemampuan mereka untuk menimbulkan kepercayaan dan keyakinan, yang meliputi item 1) Terciptanya rasa aman di lingkungan kampus 2) Terjaganya citra perguruan tinggi 3) Ketelitian pada saat melayani mahasiswa 4) Jaminan lega-litas penyelenggaran pendi-dikan 5) Tri Darma perguruan Tinggi dilaksanakan dengan baik (Assauri, 2003).

\section{f. Keberwujudan}

Keberwujudan (tangible) (Assauri, 2003) adalah Fasilitas fisik yang diberikan Perguruan Tinggi kepada mahasiswa dalam menunjang program pelayanan dalam upaya meningkatkan kepuasan mahasiswa, yang tercakup dalam item 1) Penampilan fisik pimpinan, dosen dan karyawan 2) Kebersihan dan kerapian dosen dan karyawan 3) Tata-letak ruang 4) Ruang kuliah dan pelayanan yang nyaman 5) Perlengkapan informasi dan komunikasi. 6) Perlengkapan pelayanan umum 7) Bahanbahan pembelajaran 8) Kualitas dari perlengkapan 9) Kemu-dahan berkomunikasi dengan dosen dan pimpinan jurusan. 


\section{g. Ketanggapan}

Menurut Assauri (2003), ketanggapan (responsiveness) adalah respon atau kesigapan pegawai Perguruan Tinggi dalam menyelesaikan pelayanan, membantu Mahasiswa dan memberikan pelayanan yang cepat dan tanggap, yang tercakup dalam item berikut 1) Menyelesaikan pelayanan kepada mahasiswa dengan cepat 2) Pimpinan, Dosen dan Karyawan dalam memahami kebutuhan mahasiswa cukup baik 3) Pelayanan yang dibe-rikan kepada mahasiswa, 4) Kemampuan perguruan tinggi cepat tanggap dalam meng-hadapi permasalahan maha-siswa 5) Fleksibilitas pegawai dalam memberikan waktu pelayanan konsultasi maha-siswa. 6) Pegawai menye-rahkan berkas atau dokumen pelayanan dengan cepat.

\section{B. METODE PENELITIAN}

\section{Populasi dan Sampel Penelitian}

Populasi dari penelitian ini yaitu seluruh mahasiswa Fakultas Ekonomi Universitas Negeri Yogyakarta, sedangkan sampel yang dipilih berjumlah 99 orang mahasiswa. Teknik pengambilan sampel dengan stratified random sampling. Teknik ini digunakan agar mahasiswa masing-masing jurusan dan angkatan bisa diwakili secara proporsional dan rasional.

\section{Teknik Pengumpulan Data}

Metode pengumpulan data yang digunakan adalah kuesioner. Kuesioner (angket) merupakan teknik pengumpulan data yang dilakukan dengan cara memberi seperangkat pertanyaan atau pernyataan tertulis kepada responden untuk dijawab (Sugiyono, 2009:142). Instrumen yang digunakan berupa angket/kuesioner yang diberikan kepada responden untuk mengetahui pengaruh kualitas layanan FE UNY terhadap kepuasan mahasiswa studi di FE UNY. Semi opened ended questionnaire digunakan untuk mengumpulkan informasi tentang data demografi, kualitas layanan, dan kepuasan mahasiswa di FE UNY.

\section{Teknik Analisis Data}

Dalam teknik analisis data, penulis menggunakan bantuan komputer melalui program SPSS (Statistical Package for Social Sciences). Adapun teknik analisis data yang digunakan oleh penulis meliputi: uji kualitas instrumen, uji persyaratan analisis, dan uji hipotesis. 


\section{HASIL PENELITIAN DAN PEMBAHASAN}

Penelitian ini dimaksudkan untuk mengetahui pengaruh dari faktorkeandalan, ketulusan, jaminan, keberwujudan, dan ketanggapan terhadap kepuasan mahasiswa di Fakultas Ekonomi UNY.Data yang digunakan merupakan data primer dari kuesioner yang disebarkan kepada sebagian mahasiswa yaitu sejumlah 99 mahasiswa.

Tabel 1: Distribusi Karakteristik Responden

\begin{tabular}{|l|l|c|c|}
\hline NO & KARAKTERISTIK & N & \% \\
\hline 1. & Jenis Kelamin & 53 & 53,5 \\
\hline & Laki-laki & 46 & 46,5 \\
\hline & Perempuan & & \\
\hline $\mathbf{2 .}$ & Program Studi & 16 & 16,16 \\
\hline & Pend. Akuntansi & 13 & 13,13 \\
\hline & Pend. Ekonomi & 12 & 12,12 \\
\hline & Pend. Adm. Perkntr & 21 & 21,21 \\
\hline & Akuntansi & 15 & 15,15 \\
\hline & Manajemen & 8 & 8,08 \\
\hline & Akuntansi (D3) & 6 & 6,06 \\
\hline & Pemasaran & 8 & 8,08 \\
\hline & Sekretari & & 22,22 \\
\hline 3. & Angkatan & 22 & 24,24 \\
\hline & 2008 & 24 & 32,32 \\
\hline & 2009 & 32 & 21,21 \\
\hline & 2010 & 21 & \\
\hline & 2011 & & \\
\hline
\end{tabular}

Analisis ini dilakukan untuk mengetahui tanggapan atau respon yang diberikan responden terhadap variabel-variabel penelitian.Sedangkan untuk memperoleh kesimpulan secara deskriptif, maka jawaban-jawaban tersebut kemudian ditentukan intervalnya guna memperoleh jawaban dari semua responden yang menjadi sampel dalam penelitian. Dari lima macam jawaban dalam kuesioner, diperoleh interval sebagai berikut (Junaedi, 2001):

Nilai jawaban 1,00 s/d 1,79= sangat rendah

Nilai jawaban $1,80 \mathrm{~s} / \mathrm{d} 2,59=$ rendah

Nilai jawaban 2,60 s/d 3,39= sedang

Nilai jawaban 3,40 s/d 4,19= tinggi

Nilai jawaban 4,20 s/d 5,00 = sangat tinggi 
Tabel 2: Deskripsi Keandalan (X1), Ketulusan (X2), Jaminan (X3), Keberwujudan (X4), dan Ketanggapan (X5) serta Kepuasan (Y) Dalam Persentase

\begin{tabular}{|c|r|r|r|r|r|r|l|}
\hline Interval & \multicolumn{1}{|c|}{ X1 } & \multicolumn{1}{c|}{ X2 } & \multicolumn{1}{c|}{ X3 } & \multicolumn{1}{c|}{ X4 } & \multicolumn{1}{c|}{ X5 } & \multicolumn{1}{c|}{ Y } & KATEGORI \\
\hline $1,00-1,79$ & 0 & 0 & 0 & 0 & 0 & 20,2 & Sangat Rendah \\
\hline $1,80-2,59$ & 2,0 & 1,0 & 12.1 & 0 & 14,3 & 17,2 & Rendah \\
\hline $2,60-3,39$ & 41,5 & 43,6 & 72,7 & 25,3 & 66,6 & 45,4 & Sedang \\
\hline $3,40-4,19$ & 49,5 & 55,4 & 15,2 & 63.6 & 19,1 & 14,1 & Tinggi \\
\hline $4,20-5,00$ & 7,0 & 0 & 0 & 11,1 & 0 & 3,1 & Sangat Tinggi \\
\hline
\end{tabular}

Tabel 2 di atas menunjukkan bahwa $91 \%$ Keandalan (X1) pelayanan di FE UNY masuk dalam kategori sedang dan tinggi, 99\% Ketulusan (X2) pelayanan masuk dalam kategori sedang dan tinggi, 87,9\% Jaminan (X3) pelayanan masuk dalam kategori sedang an tinggi, 89,9\% Ke-berwujudan (X4) pelayanan masuk dalam kategori sedang dan tinggi, dan 85,7\% Ketanggapan (X5) pelayanan masuk dalam kategori sedang dan tinggi, serta 59,5\% Kepuasan (Y) mahasiswa terhadap pelayanan di FE UNY masuk dalam kategori sedang dan tinggi.

Bila dikatakan bahwa kategori“"sedang” tidak diperhitungkan karena sulit diidentifikasi masuk rendah atau tinggi, maka terlihat bahwa X1, X2, X3, X4, dan X5 cenderung lebih banyak masuk kategori tinggi, sedangkan Y cenderung lebih banyak masuk kategori rendah. Dengan demikian bila hanya mendasarkan pada tabel di atas dapat dikatakan bahwa walaupun pelayanan dari FE UNY sudah masuk dalam kategori tinggi, namun kepuasan mahasiswa dalam menerima pelayanan itu masih rendah.

Tabel 3: Hasil Uji Hipotesis

\begin{tabular}{|c|c|c|c|}
\hline Variabel & $\begin{array}{c}\text { Koefisien } \\
\text { Regresi }\end{array}$ & t-hitung & Sig $t$ \\
\hline Konstanta & $-6,905$ & & \\
\hline Keandalan (X1) & 0,053 & 2,750 & 0,007 \\
\hline Ketulusan (X2) & 0.043 & 2,382 & 0,019 \\
\hline Jaminan (X3) & $-0,030$ & $-1,686$ & 0,095 \\
\hline Keberwujudan (X4) & 0,210 & 14,627 & 0,000 \\
\hline Ketanggapan (X5) & 0,039 & 2,303 & 0,028 \\
\hline \multicolumn{4}{|c|}{ Adjusted $R$ square : 0,807} \\
\hline$R$ Square $\quad:$ & \multicolumn{3}{|c|}{$: 0,814$} \\
\hline F Hitung & \multicolumn{3}{|c|}{$: 103,142$} \\
\hline Signif $F$ & \multicolumn{3}{|c|}{$: 0,000$} \\
\hline
\end{tabular}

Dari Tabel 3 di atas dapat dilihat bahwa konstanta bernilai $-6,905$, keofisien X1 sebesar 0,053, koefisien X2 sebesar 0,043, koefisien X3 sebesar -0,030, koefisien X4 
sebesar 0,210, dan koefisien X5 sebesar 0,039. Dengan demikian persamaan regresinya adalah

$$
Y=-6,905+0,053 X 1+0,043 X 2-0,03 X 3+0,210 X 4+0,039 X 5
$$

Tabel 3 di atas juga menunjukkan bahwa berturut-turut t-hitung untuk masingmasing variable independen adalah 2,$750 ; 2,382 ;-1,686 ; 14,627$; dan 2,303 , dengan nilai Sig-t sebesar, masing-masing 0,$007 ; 0,019 ; 0,095 ; 0,000 ;$ dan 0,028. Bila menggunakan t-tabel sebagai nilai pembanding, dengan mengambil alpha sebesar 5\%, maka terlihat bahwa semua nilai t-hitung lebih besar dari pada t-tabel $(1,96)$, kecuali X3, karena nilai t-hitung X3 lebih kecil dari pada t-tabel. Hal yang sama juga bisa dilakukan dengan melihat nilai Sig-t, dengan pembanding 0,05 , terlihat bahwa hanya X3 yang memiliki nilai Sig-t yang lebih besar dari pada 0,05, sedangkan variabel lain memiliki nilai Sig-t lebih kecil dari pada 0,05. Dengan demikian dapat dikatakan bahwa Keandalan (X1), Ketulusan (X2), Keberwujudan (X4), dan Ketanggapan (X5) pelayanan berpengaruh positif dan signifikan terhadap Kepuasan (Y), sedangkan Jaminan (X3) berpengaruh negative dan tidak signifikan terhadap Kepuasan (Y).

Hal ini berarti pelayanan yang selama ini dilakukan oleh FE UNY dengan variabel Keandalan, Ketulusan, Keberwujudan dan Ketanggapan berpengaruh terhadap Kepuasan yang dirasakan oleh mahasiswa di fakultas tersebut.Variabel Jaminan tidak mempengaruhi kepuasan mahasiswan.Implikasinya adalah bahwa pihak FE dapat mengoptimalkan variabel Jaminan dalam pelayanan kepada para mahasiswa agar mereka merasa puas.

Bila dianalisis dengan melihat uji secara simultan, dari tabel 3 di atas, terlihat bahwa nilai F-hitung sebesar 103,142; dengan Sig-F sebesar 0,000.Dengan demikian dapat dikatakan bahwa secara simultan kelima varibel dalam penelitian ini berpengaruh positif dan signifikan. Sedangkan nilai koefisien determinasi (R2) sebesar 0,807, artinya variansi dari kelima variabel pelayanan dalam penelitian ini mempengaruhi variansi variabel kepuasan mahasiswa sebesar 80,7 \%, sedangkan selebihnya $(19,3 \%)$ dipengaruhi oleh variabel lain yang tidak diteliti dalam penelitian ini.

\section{PENUTUP}

Dari hasil analisis dan pembahasan dapat disimpulkan bahwa: (1) Terdapat pengaruh positif dan signifikan Keandalan terhadap Kepuasan mahasiswa, (2) 
Terdapat pengaruh positif dan signifikan Ketulusan terdahap Kepuasan mahasiswa, (3) Tidak terdapat pengaruh Jaminan terhadap Kepuasan mahasiswa, (4) Terdapat pengaruh positif dan signifikan Keberwujudan terhadap Kepuasan mahasiswa, (5) Terdapat pengaruh positif dan signifikan Ketanggapan terhadap Kepuasan mahasiswa, (6) Secara simultan kelima variable berpengaruh positif dan signifikan terhadap Kepuasan mahasiswa.

Saran yang dapat diberikan dari hasil penelitian ini adalah bahwa variabelvariabel yang sudah berpengaruh terhadap kepuasan mahasiswa agar terus ditingkatkan supaya mahasiswa memperoleh kepuasan lebih tinggi lagi.Sedangkan pihak FE UNY perlu untuk meningkatkan jaminan pelayanan bagi para mahasiswa agar kepuasan yang mereka dapat meningkat.

\section{E. DAFTAR PUSTAKA}

Anthony, Robert N. dan Vijay Govindaraja.(2009). Sistem Pengendalian Manajemen. Jakarta: Salemba Empat.

Arikunto, Suharsimi. (2006). Prosedur Penelitian Suatu Pendekatan Praktik. Jakarta: PT Asdi Mahasat

Assauri, Sofjan, 2003, Customer Service yang baik Landasan Pencapaian Customer Satisfaction, Usahawan, 01 (januari) : 25-30.

Caruana, Albert, Michael T. Ewing, B. Ramaseshan, 2000, Assessment of the Three Column Format Servqual : An Experiment Approach., Journal of Business Research, 49 : 57-65.

Chloridiany Aulia, 2003, Demi Uang, Muncul Label Hura-hura, Jawa Pos, 24 April

Cooper, Donald R., and Pamela S. Schindler. 2001 Business Research Method, Seventh edition, Me. Graw-Hill, New York

Farre'i Andrew, Anne Souchon \& Geoffrey.Durden, 2001, Service Quality. Enhancement: The Role of Employees' Service Behaviors, Aston Business School Research Institute, Aston University, Juli.

Ferdinand, Augusty. 2000, Structural Equation Modeling Da/am Penelitian, Badan Penerbit Universitas Diponegoro, Semarang 
Parrel Andrew, Anne Soucjion \& Geoffrey.Durden, 2001, Service Quality. Enhancement: The Role of Employees' Service Behaviors, Aston Business School Research Institute, Aston University, Juli.

Ferdinad, Augusty. 2000, Structural Equation Modeling Da/am Penelitian, Badah ' Penerbit Universitas Diponegoro, Semarang

Graperitine, Terry, Internet Maret 2003, The History and Future of Service Quality Assessment : Connecting Customer Needs and Expectations to Busine ss Proceses.

Junaedi, M.F. Sheelyama, C. Mariiana Junaedi, 2001, Mengukur Persepsi Harapan dan Kualitas Jasa Konsumen dengan Model Service Quality, Jurnal Widya Manajemen, vol. 1. No. 2, Agustus : 96-107.

_, 2000, Marketing Management, International edition, Prentice -Hall International, Inc.

Lupiyoadi, Rambat. 2001, Manajemen Pemasaran Jasa, Edisi pertama, Penerbit Salemba Empat, Jakarta.

Mohsin, Asad, 2003, Service Quality Assessment of Restaurants in Darwin, NT, Australia, Journal of Hospitality and Tourism Management, 10 (Januari):23.

Neng-Pailin, Hung-Chang Chik, Yi - Ching Hsieh, 2001, Investigating The Relationship between Service Provider's Personality and Customers' Perceptions of Service Quality a Cross Gender, Total Qua/fry Management, 2 (Januari); 57.

Darker, Cathy, Brian P. Mathews, 2001, Customer Satisfaction. Contrasting Academic and Consumer's Inter - pretations, Marketing Intelligence \& Planning, 19/1 : 38-44.

Parker Cathy, Brian P. Mathews. 2001, Customer Satisfacti on: Contrasting Academic and Consumer's Interpretation, Marketing Intelligence \& Planning, 19/1:3844.

Rangkuti, Freddy. 2001. Riset Pemasaran. Ceta'kan keempat, Penerbit PT Gramedia Pustaka Utama bekerja sama dengan Sekolah Tinggi Ekonomi IBM, Jakarta. 
Said, Syahnur. 2002. Faktor -Faktor Strategis Yang Mempengaruhi Kualitas Pelayanan Dan Kinerja Perguruan Tinggi Negeri Dan Swasta Di Indonesia. Disertasi tidak dipublikasikan, Program Pasca Sarjana Universitas Airlangga, Surabaya.

Sarmanu, 2003, Validitas dan Reliabilitas instrument, Pelatihan Structural Equation Modelling, Lembaga penelitian Unair.

Sidik Abdulah, 2003, Pemerataan Pendidikan yang Kebablasan, Jawa Pos, 23 April.

Siu, Noel Y.M., Jeff Tak -Hing Cheung, 2001, A Measure of Retail Service Quality, Marketing Intelligence \&Planning., 19/2 : 88-96.

Solimun. 2002. Structural Equation Modeling (SEM) Lisrel Dan Amos. Cetakan I, Penerbit Universitas Negeri Malang.

Soehendro Bambang. 1996, Kerangka Pengembangan Pendidikan Tinggi Jangka Panjang 1996 - 2005, Departernen Pendidikan dan Kebudayaan Direktorat H Jenderal Pendidikan Tinggi, Jakarta.

Stoner, James, A.F., Freeman, R. Edward, Gilbert Jr., Daniel, R. 1996, Manajemen, terjemahan, Alexander Sindoro, Penerbit PT Prinhallindo, Jakarta. 2000. Statistik. Teori Dan Aplikasi. Edisi keenam. Penerbit Erlangga, Jakarta.

Suter Tracy A. 20U3, The Integration of Internal Marketing Into The Organizational Culture of Service Firm, University of Arkansas, : 25 September 2003.

Too, Leanne H.Y., Anne L. Souchon \& Peter C. Thirkett, 2000, Relationship Marketing 'and Customer Loyalty in Retail Setting : A Dyadic Exoloration, Aston Business School Research Institute, Aston University, Juni.

Trybi'S, E., Kumar R., K. Klassen, 2000, Improving Service Quality. A Study of Parking Satisfaction at a University Campus, Proceedings of the 12' Annual I CSU-POM Conference California State University, Sacramento, February 2526 : ft 19-25. 